\title{
High sodium intake of children through 'hidden' food sources and its association with the Mediterranean diet: the GRECO study
}

\author{
Emmanuella Magriplis ${ }^{a}$, Paul Farajian ${ }^{a}$, George D. Pounis ${ }^{a}$, Grigoris Risvas ${ }^{a}$, \\ Demosthenes B. Panagiotakos $^{b}$ and Antonis Zampelas ${ }^{a}$
}

Objectives Sodium is the mineral that has been, mainly, linked to hypertension and cardiovascular disease. It is found naturally in many foods, but is also used in the food industry and manufacturing. Identification of total sodium intake, as well as 'hidden' sodium intake from food sources early in life is necessary.

Methods Four thousand, five hundred and eighty children aged 10-12 years were enrolled, in a cross-sectional, population-based survey. Among other measurements, dietary data were obtained by a semi-quantitative food frequency questionnaire, and sodium intake was calculated. High sodium consumption was considered an intake over $2200 \mathrm{mg} /$ day. Adherence to the Mediterranean dietary pattern was evaluated using the Mediterranean Diet Quality Index for children and adolescent score (KIDMED score).

Results Twenty-three percent of Greek children had sodium intake which exceeded the $2200 \mathrm{mg} /$ day recommendation, excluding salt added at table and during cooking. Sodium intake was found elevated in children with moderate and high adherence to the Mediterranean Diet. Additionally, 1 unit increase in KIDMED score (i.e. higher adherence) was associated with $10 \%$ [odds ratio (OR) 1.10 , 95\% confidence interval $(\mathrm{Cl}) 1.07-1.13$ ] increased likelihood of consuming sodium above the median intake (i.e. $>1500 \mathrm{mg} /$ day). Thirty-four percent of sodium intake

\section{Introduction}

Hypertension is a global burden which has been associated with renal and cardiovascular disease, the latter being the leading cause of death in developed countries. Worldwide, nearly 1 billion adults have hypertension, and $17-30 \%$ of hypertension cases can be attributed to excess dietary sodium $[1,2]$. Sodium is a mineral found naturally in many foods but is also used greatly in processed foods. It is noteworthy that in some countries, it has been suggested that reducing sodium consumption to the recommended intakes $(<2200 \mathrm{mg} /$ day) will likely reduce hypertension and hypertension-related cardiovascular disease by 30 and $8.6 \%$, respectively [3]. High blood pressure (BP) levels can be observed in children and a significant number of children have elevated BP levels without having any underlying disease. High BP levels in childhood should be regularly reassessed and nonpharmacological or pharmacological interventions should be promptly initiated from 'hidden' sources came from bread, processed cereals and white cheese.

Conclusions Greek children have an elevated sodium intake from 'hidden' sources and main contributors are foods which are recommended to be consumed on a daily basis according to the Mediterranean Diet Pyramid. These findings should induce manufacturers to reduce the amount of sodium added during processing of 'healthy' foods, especially bread and cheese. J Hypertens 29:1069-1076 (C) 2011 Wolters Kluwer Health | Lippincott Williams \& Wilkins. Journal of Hypertension 2011, 29:1069-1076

Keywords: children, Mediterranean diet, public health, sodium food sources, sodium intake

Abbreviations: FFQ, Food Frequency Questionnaire; KIDMED, Mediterranean Diet Quality Index for children and adolescents; MVPA, moderate through vigorous physical activity; PAQ-C, Physical Activity Questionnaire for older Children

aUnit of Human Nutrition, Department of Food Science and Technology, Agricultural University of Athens and ${ }^{\mathrm{b}}$ Department of Science of Dietetics Nutrition, Harokopio University, Athens, Greece

Correspondence to Antonis Zampelas, PhD, Associate Professor of Human Nutrition, Unit of Human Nutrition, Department of Food Science and Technology, Agricultural University of Athens lera Odos 75, Athens 11855, Greece Tel: +30 210 5294701; fax: +30 2105294701; e-mail: azampelas@aua.gr

Received 30 September 2010 Revised 13 February 2011 Accepted 18 February 2011

because high BP levels in childhood may lead to hypertension and related cardiovascular diseases in later life [4].

Regarding sodium intake modification, there is controversy as to how sodium intake can be decreased in individuals, as well as in populations, and which public health measures should be taken in order to help reduce total sodium daily intake. Therefore, identification of food sources of sodium in modern diets is critical. To date many researchers have focused on the sodium content of poor nutritional quality foods that children consume [5]. Sodium, however, can also be found hidden in 'healthy' foods such as whole wheat bread and processed cereal, foods consumed largely in a Mediterranean-type diet. Although the health benefits of the Mediterranean diet are widely acknowledged, there is still inconsistency regarding the association of adherence to the Mediterranean diet and total sodium intake. In particular, the 
Mediterranean diet has been described as a diet abundant in plant foods, minimally processed, olive oil as the main fat source, low to moderate dairy and wine intake, low intake of red meat, and sparse sugar intake [6]. Although research has shown that specific foods which characterize the Mediterranean diet have preventive effects on chronic diseases, such as fruits and vegetables, olive oil and nuts and unprocessed cereals [7-16], little is known on the contribution of these foods to the total sodium intake in the modern diet.

Therefore, in the present work, and under the context of the Greek Childhood Obesity study (GRECO), the daily dietary sodium intake (excluding table salt and salt added during cooking) of 10-12 years old Greek children, was studied, within the context of the Mediterranean diet pattern.

\section{Methods}

\section{Participants}

The GRECO study was carried out from October to May 2009. The sampling included all regions of the country (i.e. Attica, Sterea Ellada and Evia, Macedonia, Peloponnesus, Epirus, Thessaly, Thrace, Aegean islands, Ionian Islands and Crete). From the aforementioned regions a number of 130 randomly selected public primary schools (through the listings provided by the Ministry of Education) were invited to participate. The number of children to be enrolled in each region was proportional to the total population of the region, based on data provided by the National Statistics Service of Greece. Thus, a total of 5850 schoolchildren (fifth and sixth grade) were invited for potential inclusion. However, the number of schools that agreed to participate in the study was 117 from all over the country and signed parental consent forms were obtained for 4965 of 5850 children $(84.9 \%$ participation rate) and were finally enrolled in the study. After checking the quality of the data obtained from the enrolled children, the final sample consisted of 4580 children ( $49 \%$ men and $51 \%$ women) with a mean age of $10.9 \pm 0.75$ years, with the 52.0 and $48 \%$ coming from large urban (i.e. $>1000000$ pop.) and urban and semi-urban areas (i.e. 10000 to 1000000 pop.), respectively.

\section{Bioethics}

The retrieved data were confidential, and the study followed the ethical considerations provided by the World Medical Association (52nd WMA General Assembly, Edinburgh, Scotland, October 2000). The research was approved by the Hellenic Ministry of Education (Department of Primary Education) as the law provides in Greece for any studies conducted in the school environment, during formal school hours, and the Agricultural University of Athens Research Committee. Prior to measurements' initiation an extended letter explaining the aims of the study was sent to the principal of each school and each parent or guardian was provided with a letter explaining the aims of the study and a consent form. Those parents who agreed to participate in the study had to sign the consent form and send it back to the school in order to be collected.

\section{Measurements}

The measurements were conducted by investigators and staff of the Unit of Human Nutrition of the Agricultural University of Athens. All investigators followed a series of planning meetings and were trained in survey methods that included practical experience in weighing and measuring techniques. Additionally, before the initiation of the study all investigators followed a 2-week pilot practice period in primary schools that were not included in the final study sample in order to get familiarized with the procedures. All study sites used the same measuring equipment and procedures and in each class the investigators' team consisted of at least two people. All measurements were performed during morning hours.

\section{Dietary and eating behavior assessment}

Dietary assessment was based on a validated self-reported, semi-quantitative Food Frequency Questionnaire (FFQ), consisting of 48 food items commonly used in the local Greek cuisine [17]. All participants were asked about their usual frequency of consumption of the food items (average over the past year) with the response categories ranging from never, 1-2 times per month, to everyday. Pictures of standard size of the food portions were used to help participants visualize the regular portion and quantify the portion of the food item they usually consumed. Specifics on the type of food consumed were also asked for (such as whole wheat bread vs. white bread, brown rice vs. white, low-fat dairy products vs. full-fat, sugar-free soft drinks vs. regular, etc.). The assessment of sodium intake through consumption of various food groups was performed using food composition tables of US Department of Agriculture [18]. The evaluation of repeatability of dietary information regarding sodium intake were tested in a sample of 21 girls and 23 boys (aged $10-12$ years) from one school unit in Athens, applying the semi-quantitative FFQ two times (within a 30-day interval) in the same children. Results showed very good repeatability between the two measurements (Spearman's rho $=0.82, P<0.001$, $\%$ of agreement using Bland-Altman graphical method $=93.2 \%$ ). Furthermore relative validity of such information was assessed using 3-day recalls which applied 30 days after the FFQ in a second sample of 20 girls and 13 boys (aged 10-12 years) from the same school unit. Very good relative validity was revealed regarding sodium consumption resulting from FFQ and 3-day recalls (Spearman's rho $=0.57, P<0.001$, \% of agreement using BlandAltman graphical method $=91.0 \%)$.

\section{Assessment of Mediterranean diet pattern}

The KIDMED index (Mediterranean Diet Quality Index for children and adolescents) was used to evaluate 
the degree of adherence to the Mediterranean diet [19]. The index comprises of 16 yes or no questions. Questions denoting a negative connotation with respect to the Mediterranean diet were assigned a value of -1 and those with a positive aspect +1 . The total score ranged from -4 to 12 .

\section{Physical activity, anthropometric assessment and blood pressure measurements}

All participants were asked to complete the Physical Activity Questionnaire for Older Children (PAQ-C) [20]. The instrument is designed for use in older children aged $8-14$ years and consists of nine questions structured to discern moderate to vigorous physical activity (MVPA) during the past 7 days. The summary score for the PAQ-C is the average of the sum of the nine questions using a 1-5 scale and it is designed to be used during the school year, rather than summer vacation or holiday periods.

Body weight was recorded to the nearest $100 \mathrm{~g}$ with the use of a digital scale (Tanita TBF 300) and with patients standing without shoes in light clothing. Standing height was measured using a portable stadiometer (Leicester height measure) to the nearest $0.1 \mathrm{~cm}$ without shoes, with the head positioned according to the Frankfort plane. Body mass index (BMI) was calculated by dividing weight $(\mathrm{kg})$ by standing height squared $\left(\mathrm{m}^{2}\right)$. Percentage of body fat $(\% \mathrm{BF})$ and body fat mass were estimated by the foot to foot impedance method (Tanita TBF 300) with children standing barefoot. Obesity and overweight among children were evaluated using the International Obesity Task Force (IOTF) age and sex-specific BMI cut-off criteria [21].

Blood pressure was measured using an oscillometric device (UA-787 oscillometric blood pressure monitor, A\&D Company), equipped with the right type of cuff for children of this age. During the measurements children were calm, in a sitting position with their back supported, with the right arm resting on a solid supporting surface at heart level, and at least $10 \mathrm{~min}$ at rest [22]. Two subsequent measurements were taken with a 5 -min interval in order to familiarize children with the procedure and the diastolic and systolic BP values of the second measurements were recorded.

\section{Statistical analysis}

Normally distributed continuous variables are presented as mean $\pm \mathrm{SD}$, skewed as median (first, third quartiles) and categorical variables as frequencies. The normality of continuous variables was tested graphically according to P-P plots. Comparisons of continuous variables between groups of study were performed using the independent $t$ test or one-way ANOVA, for the normally distributed variables and the Mann-Whitney $U$-test or KruskalWallis test, for the skewed. Associations between categorical variables were tested using the Pearson's chi- squared test. Repeatability and relative validity of dietary information regarding sodium intake were tested using Spearman's rho and Bland-Altman method. High sodium consumption was considered over $2200 \mathrm{mg} /$ day from food sources alone [23]. According to the KIDMED scoring system [19], only $4.5 \%$ of the children $(N=205)$ had an optimal score $(\geq 8)$, therefore children with average and high scores were pooled together into one group of 'moderate and high adherers' to the Mediterranean diet, with a KIDMED score higher than the median for this population (i.e. $>4$ ). Whereas children with a KIDMED score equal or lower than the median were classified as 'low adherers'. Multiple logistic regression analysis adjusted for age, sex, BMI and physical activity was used to evaluate the association between adherence to the Mediterranean diet on the likelihood of consuming high sodium intake from different food resources (dependent outcome). Results are presented as odds ratios (ORs) and their corresponding 95\% confidence intervals (CIs). Hosmer-Lemeshow statistic was used to test the models' goodness of fit. All tested hypotheses were two-sided. $P$ value less than 0.05 was considered as statistically significant. SPSS version 18 software was used for all calculations (SPSS Inc., Chicago, Illinois, USA).

\section{Results}

In Table 1 various socio-demographic, anthropometric and lifestyle characteristics of the children are presented, according to their level of sodium intake, other than table salt. Using the recommended cut-offs it was observed that $23 \%$ of the total sample had high sodium intake ( $>2200 \mathrm{mg} /$ day), without taking into account added salt at the table or while cooking. Moreover, boys were more likely to be categorized in high sodium consumption than girls $(P<0.001) ; 31.6 \%$ of children who had high total sodium consumption were overweight or obese; children with high sodium intake were more physically active, but also had better adherence to the Mediterranean diet than participants with low intake. No significant difference was observed as regards the level of sodium intake and age groups, or region of living (urban or rural). Moreover, no association was observed between sodium intake and BP levels, even after adjusting for sex and age of the children. Concerning body fat measurement results, body fat mass was positively correlated with BMI (Pearson's rho $=0.897, P<0.001)$, and negatively correlated with sodium intake (Spearman's rho $=-0.180, P<0.001$ ).

Then, increased sodium intake from different food sources was evaluated by the level of adherence to the Mediterranean diet (Table 2). Children that reported moderate and high adherence to the Mediterranean diet (i.e. KIDMED score $>4$ ) had higher sodium intake from the majority of the food groups $(P<0.001)$, by the exception of pizza, hamburgers, souvlaki (a type of meat), saltines (including crisps, crackers, cheese sticks) and cakes $(P>0.05)$. 
Table 1 Socio-demographic, anthropometric and lifestyle characteristics of the participants, by sodium consumption from foods other than table salt and cooking salt

\begin{tabular}{|c|c|c|c|c|c|}
\hline & $\begin{array}{l}\text { Low total sodium intake } \\
(<1500 \mathrm{mg} / \text { day })^{\mathrm{a}}\end{array}$ & $\begin{array}{c}\text { Moderate total sodium } \\
\text { intake }(1500-2200 \mathrm{mg} / \text { day })\end{array}$ & $\begin{array}{l}\text { High total sodium } \\
\text { intake (>2200 mg/day) }\end{array}$ & Total sample & $P^{\mathrm{b}}$ \\
\hline$N$ & $2570(56.1 \%)$ & 959 (20.9\%) & $1051(23 \%)$ & 4580 & \\
\hline Age group (\%) & & & & & 0.14 \\
\hline 10 years & 25.2 & 21.6 & 22.5 & 23.6 & \\
\hline 11 years & 47.6 & 49.7 & 48.2 & 48.3 & \\
\hline 12 years & 27.2 & 28.7 & 29.3 & 28.1 & \\
\hline Male sex $(\%)$ & 42.2 & 48.9 & $60.3^{* *}$ & 49.0 & $<0.001$ \\
\hline BMI $\left(\mathrm{kg} / \mathrm{m}^{2}\right)$ & $20.7 \pm 3.9$ & $20.2 \pm 3.7$ & $19.5 \pm 3.6^{*}$ & $20.3 \pm 3.8$ & $<0.001$ \\
\hline Body fat mass $(\mathrm{kg})$ & $11.2 \pm 6.6$ & $10.3 \pm 6.3$ & $8.9 \pm 5.8$ & $10.4 \pm 6.4$ & $<0.001$ \\
\hline Percentage of body fat (\%) & $22.4 \pm 8.9$ & $20.8 \pm 8.7$ & $18.8 \pm 8.3$ & $21.1 \pm 8.9$ & $<0.001$ \\
\hline Overweight/obese (\%) & 45.0 & 39.6 & $31.8^{* *}$ & 40.1 & $<0.001$ \\
\hline Physical activity $(0-5)$ & $2.92 \pm 0.60$ & $2.93 \pm 0.58$ & $3.02 \pm 0.62^{*}$ & $2.95 \pm 0.60$ & $<0.001$ \\
\hline KIDMED score (-4 to 12$)$ & $3.55 \pm 2.17$ & $4.21 \pm 2.12^{* *}$ & $3.86 \pm 2.25^{*}$ & $3.78 \pm 2.20$ & $<0.001$ \\
\hline
\end{tabular}

${ }^{a}$ Total dietary sodium consumption was classified to low, moderate and high intake (i.e. $<1500,1500-2200,>2200$ mg/day) using European Union recommendations. ${ }^{\mathrm{b}} P$ values were derived through one-way ANOVA test for normally distributed variables, Kruskal-Wallis for skewed and Pearson's $\chi^{2}$ for categorical data. ${ }^{*} P<0.05$ from post-hoc comparisons between high, moderate vs. low sodium intake, after correcting the $P$ value with the Bonferroni rule. ${ }^{* *} P<0.01$ from post-hoc comparisons between high, moderate vs. low sodium intake, after correcting the $P$ value with the Bonferroni rule.

Moreover, in Fig. 1, the major food items that contribute to sodium intake are presented. The greater sources of sodium in children's diet were pizza and white cheese, whereas healthy foods, conferred more in total sodium consumption than junk foods ( 34 and $27 \%$ of total sodium intake, correspondingly). It should be noted that children with moderate and high adherence to the Mediterranean diet (i.e. KIDMED score $>4$ ) had higher consumption of

Table 2 Sodium intake from different sources, by level of adherence to the Mediterranean diet using KIDMED score

\begin{tabular}{|c|c|c|c|c|}
\hline & $\begin{array}{l}\text { Low adherence to } \\
\text { Mediterranean diet }\end{array}$ & $\begin{array}{l}\text { Moderate and high } \\
\text { adherence to Mediterranean diet }\end{array}$ & Total sample & $P^{\mathrm{a}}$ \\
\hline$N$ & 2876 & 1704 & 4580 & \\
\hline Sex $(\%)$ & & & & 0.257 \\
\hline Boys & 61.9 & 38.1 & 49.0 & \\
\hline Girls & 63.5 & 36.5 & 51.0 & \\
\hline Weight status (\%) & & & & 0.348 \\
\hline Overweight & 64.1 & 35.9 & 29.1 & \\
\hline Obese & 63.6 & 36.4 & 11.0 & \\
\hline BMI $\left(\mathrm{kg} / \mathrm{m}^{2}\right)$ & $20.3 \pm 3.8$ & $20.2 \pm 3.8$ & $20.3 \pm 3.8$ & 0.311 \\
\hline Percentage of body fat (\%) & $21.2 \pm 8.9$ & $20.8 \pm 8.8$ & $21.1 \pm 8.9$ & 0.193 \\
\hline IPAQ-C & $2.9 \pm 0.6$ & $3.0 \pm 0.6$ & $2.9 \pm 0.6$ & $<0.001$ \\
\hline $\mathrm{DBP}(\mathrm{mmHg})$ & $71.2 \pm 10.6$ & $70.9 \pm 10.4$ & $71.1 \pm 10.5$ & 0.47 \\
\hline SBP $(\mathrm{mmHg})$ & $108.5 \pm 13.0$ & $108.1 \pm 13.0$ & $108.4 \pm 13.0$ & 0.39 \\
\hline \multicolumn{5}{|c|}{ Sodium intake from different food groups $(\mathrm{mg} / \text { day })^{\mathrm{b}}$} \\
\hline Processed cereals & $29.6(0,133)$ & $104(29.6,207)$ & $59.2(10.4,133)$ & $<0.001$ \\
\hline Bread & $53.2(4.7,120)$ & $59.8(26.6,138)$ & $53.2(9.32,120)$ & $<0.001$ \\
\hline Beans & $2.8(0,8.3)$ & $11(2.9,16.6)$ & $5.5(0.97,11)$ & $<0.001$ \\
\hline Potatoes & $46.4(16.2,139)$ & $92.8(32.5,186)$ & $48.7(16.2,48.7)$ & $<0.001$ \\
\hline Bread products & $7.3(0,18.8)$ & $14.6(3.6,29.2)$ & $7.3(2.55,29.2)$ & $<0.001$ \\
\hline Cabbage family & $0(0,3.5)$ & $2.5(47.9,431)$ & $1.2(0,3.5)$ & $<0.001$ \\
\hline Cheese, white & $95.8(0,335)$ & $215(47.9,431)$ & $95.8(16.8,335)$ & $<0.001$ \\
\hline Cheese, yellow & $41.5(0,166)$ & $82.9(14.5,187)$ & $41.5(0,166)$ & $<0.001$ \\
\hline Cheese, low in fat & $0(0,13.2)$ & $4.6(0,26.3)$ & $0(0,13.2)$ & $<0.001$ \\
\hline Cold cuts (processed meat) & $55.8(0,223)$ & $55.8(19.5,223)$ & $55.8(9.8,223)$ & $<0.001$ \\
\hline Meat, red & $10(3.5,20)$ & $20(7,40)$ & $10(3.5,20)$ & $<0.001$ \\
\hline Meat, white & $13.6(6.8,38.8)$ & $19.4(13.6,38.8)$ & $19.4(6.8,38,8)$ & $<0.001$ \\
\hline Fish & $14(4.9,28)$ & $28(9.8,42)$ & $14(4.9,28)$ & $<0.001$ \\
\hline Pizza & $188(65.8,376)$ & $188(132,376)$ & $188(65.8,376)$ & 0.34 \\
\hline Hamburger & $26.6(0,26.6)$ & $26.6(0,26.6)$ & $26.6(0,26.6)$ & 0.56 \\
\hline Souvlaki & $14.4(14.4,41)$ & $14.4(14.4,41)$ & $14.4(14.4,41)$ & 0.58 \\
\hline Potatoes, fried & $27.7(9.7,83.2)$ & $41.6(19.4,111)$ & $27.7(9.7,111)$ & $<0.001$ \\
\hline Saltines & $38.1(0,109)$ & $38.1(19.1,109)$ & $38.1(0,109)$ & 0.38 \\
\hline Cake & $23.2(11.6,66.4)$ & $31.1(11.6,66.4)$ & $23.2(11.6,66.4)$ & 0.12 \\
\hline Pies & $18.1(0,51.8)$ & $45.3(18.1,10.4)$ & $18.1(18.1,104)$ & $<0.001$ \\
\hline Soft drinks & $1.4(0,8)$ & $2.0(1.4,8.0)$ & $1.4(0,8)$ & $<0.001$ \\
\hline Total sodium intake (mg/day) & $1410(839,2258)$ & $1576(1091,2330)$ & $1481(932,2287)$ & $<0.001$ \\
\hline Total sodium intake $(\%)$ & & & & $<0.01$ \\
\hline$<1500 \mathrm{mg} /$ day & 57.7 & 53.4 & 56.1 & \\
\hline $1500-2200 \mathrm{mg} /$ day & 19.2 & 23.9 & 20.9 & \\
\hline$\geq 2200 \mathrm{mg} /$ day & 23.1 & 22.6 & 23.0 & \\
\hline
\end{tabular}

Low MD adherence: KIDMED score $\leq 4$; moderate and high MD adherence: KIDMED $>4$. ${ }^{\text {a }} P$ values were derived using Mann-Whitney test for skewed variables and Pearson's $\chi^{2}$ for categorical data. ${ }^{b}$ Dietary sodium intake from different sources is presented as median (25th percentile, 75 th percentile) because its distribution was skewed in all cases. 


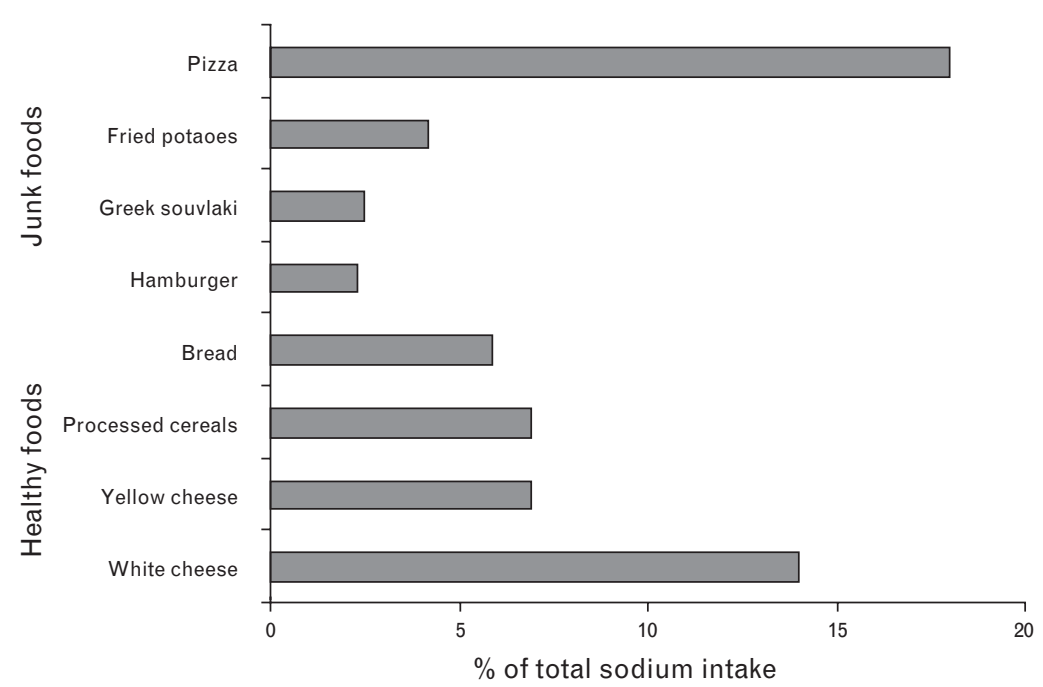

Sodium intake from healthy or junk foods as percentage of total consumption other than table salt and salt added during cooking.

these foods ( $P$ values for all $<0.05)$, with the exception of pizza, hamburgers and souvlaki.

In addition, the level of adherence to the Mediterranean diet was associated with sodium intake from various food sources. In particular, unadjusted analyses (Table 3) revealed that 1 unit increase in the KIDMED score was associated with $4-50 \%$ (i.e. ORs varied from 1.04 to 1.50 , all $P$ values $<0.05)$ increased likelihood of consuming sodium intake above the median value for the majority of foods. These results were confirmed even after adjusting for age, sex, BMI and physical activity. The impact of healthy dietary habits (as assessed through the KIDMED score) on the likelihood of high sodium intake were not significant regarding hamburgers and saltines $(P$ values $>0.05)$. Moreover, 1 unit increase in

Table 3 Results from multiple logistic regression analyses that evaluated the association between children's adherence to the Mediterranean diet (using the KIDMED score as independent variable) on likelihood of consuming high sodium (i.e. above the median as the binary dependent outcome) from different food sources (other than table and cooking salt)

\begin{tabular}{|c|c|c|c|c|}
\hline \multirow[b]{2}{*}{ Sodium higher than the median intake from various foods ${ }^{a}$ (dependent) } & \multicolumn{2}{|c|}{ Unadjusted } & \multicolumn{2}{|c|}{$\begin{array}{c}\text { Adjusted for age, sex, physical } \\
\text { activity and BMI }\end{array}$} \\
\hline & $\begin{array}{l}\text { OR for } 1 \text { unit } \\
\text { in KIDMED }\end{array}$ & $95 \% \mathrm{Cl}$ & $\begin{array}{l}\text { OR for } 1 \text { unit } \\
\text { in KIDMED }\end{array}$ & $95 \% \mathrm{Cl}$ \\
\hline$>59.2 \mathrm{mg} /$ day from processed cereals & $1.32^{*}$ & $1.28,1.36$ & $1.31^{*}$ & $1.27,1.35$ \\
\hline$>53.2 \mathrm{mg} /$ day from bread & $1.20^{*}$ & $1.17,1.24$ & $1.20^{*}$ & $1.17,1.23$ \\
\hline$>7.3 \mathrm{mg} /$ day from bread products & $1.22^{*}$ & $1.19,1.25$ & $1.20^{*}$ & $1.17,1.24$ \\
\hline$>5.5 \mathrm{mg} /$ day from beans & $1.50^{*}$ & $1.45,1.55$ & $1.50^{*}$ & $1.45,1.55$ \\
\hline$>48.7 \mathrm{mg} /$ day from potatoes & $1.19^{*}$ & $1.16,1.23$ & $1.18^{*}$ & $1.15,1.22$ \\
\hline$>1.2 \mathrm{mg} /$ day from cabbage family & $1.30^{*}$ & $1.26,1.33$ & $1.29^{*}$ & $1.26,1.33$ \\
\hline$>95.8 \mathrm{mg} /$ day from white cheese & $1.26^{*}$ & $1.23,1.30$ & $1.25^{*}$ & $1.22,1.29$ \\
\hline$>41.5 \mathrm{mg} /$ day from yellow cheese & $1.19^{*}$ & $1.16,1.22$ & $1.18^{*}$ & $1.15,1.21$ \\
\hline$>0.1 \mathrm{mg} /$ day low in fat cheese & $1.13^{*}$ & $1.10,1.16$ & $1.12^{*}$ & $1.09,1.15$ \\
\hline$>55.8 \mathrm{mg} /$ day from cold cuts & $1.09^{*}$ & $1.06,1.11$ & $1.08^{*}$ & $1.05,1,11$ \\
\hline$>10 \mathrm{mg} /$ day from red meat & $1.18^{*}$ & $1.15,1.21$ & $1.16^{*}$ & $1.13,1.20$ \\
\hline$>19.4 \mathrm{mg} /$ day from white meat & $1.19^{*}$ & $1.16,1.23$ & $1.18^{*}$ & 1.151 .22 \\
\hline$>14 \mathrm{mg} /$ day from fish & $1.35^{*}$ & $1.31,1.39$ & $1.33^{*}$ & $1.30,1.38$ \\
\hline$>188$ mg/day from pizza & $1.04^{*}$ & $1.01,1.06$ & $1.04^{*}$ & $1.01,1.07$ \\
\hline$>26.6 \mathrm{mg} /$ day from hamburger & 0.99 & $0.96,1.02$ & 0.99 & $0.96,1.02$ \\
\hline$>14.4 \mathrm{mg} /$ day from souvlaki & $1.23^{*}$ & $1.19,1.28$ & $1.23^{*}$ & $1.18,1.27$ \\
\hline$>27.7 \mathrm{mg} /$ day from fried potatoes & $1.13^{*}$ & $1.10,1.16$ & $1.13^{*}$ & $1.10,1.16$ \\
\hline$>38.1 \mathrm{mg} /$ day from saltines & $1.02^{*}$ & $1.00,1.05$ & $1.02^{*}$ & $0.99,1.04$ \\
\hline$>23.2 \mathrm{mg} /$ day from cake & $1.07^{*}$ & $1.04,1.10$ & $1.06^{*}$ & $1.03,1.09$ \\
\hline$>18.1 \mathrm{mg} /$ day from pies & $1.10^{*}$ & $1.07,1.13$ & $1.10^{*}$ & $1.07,1.13$ \\
\hline$>1.4 \mathrm{mg} /$ day from soft drinks & $1.12^{*}$ & $1.09,1.15$ & $1.10^{*}$ & $1.07,1.14$ \\
\hline Total sodium intake over EU upper level (>1500 mg/day) & $1.10^{*}$ & $1.07,1.13$ & $1.10^{*}$ & $1.07,1.13$ \\
\hline Total sodium intake over EU recommended consumption (>2200 mg) & 1.02 & $0.99,1.05$ & 1.02 & $0.98,1.05$ \\
\hline
\end{tabular}

${ }^{\text {a }}$ Sodium intake over the median for this population was evaluated as high consumption for each food group. ${ }^{*} P<0.05$. 
KIDMED score was associated with $10 \%$ increase in likelihood of consuming total sodium greater than 1500 $\mathrm{mg} / \mathrm{day}$ (which is the EU upper level), although this association was not significant when extreme total sodium intake (i.e. $>2200 \mathrm{mg} /$ day) was considered as the outcome $(P>0.05)$. At this point it should be noted that the average level of adherence to the Mediterranean diet was low to moderate in both sexes (Table 1).

\section{Discussion}

The main finding of the present work was that dietary sodium intake, other than table salt and salt added during cooking, is above the current guidelines in $23 \%$ of the Greek children. A secondary finding was that this high sodium intake was observed even in children that reported to be closer to the Mediterranean dietary pattern. Nevertheless, it should be underlined that only $4.5 \%$ of children had an optimal adherence to the Mediterranean diet (KIDMED score $\geq 8$ ). These extremely low levels of adherence imply that the positive association between dietary sodium intake from food sources and the adherence to the Mediterranean diet scheme, basically concerns children with low and moderate adherence to this traditional dietary pattern, although the main contributors of sodium intake were foods which are recommended to be consumed on a daily basis and are placed at the bottom of the pyramid. Finally, another important finding of the GRECO study was the alarming magnitude of childhood obesity in Greece, since the overall prevalence of overweight and obesity exceeded $40 \%$ of the population of schoolchildren aged $10-$ 12 years.

In addition, the fact that a further $20.9 \%$ of the children had a moderate sodium intake (between 1500 and $2200 \mathrm{mg} /$ day), but only via foods, and without taking into account the salt added at the table and the salt added during cooking, could imply that a significant and alarming proportion of the children consumes sodium above the guidelines, which makes it an important public health issue, in Greece. Sex and physical activity were also associated with high sodium consumption. In particular, boys and physically active children had higher sodium intakes than girls and less physically active children. The key sodium contributors were pizza, white cheese, processed cereals and breads.

Our results are in agreement with results from studies performed in other countries too [24-27]. In particular, Pavadhgul et al. [26] found that dietary sodium intake among Thai University students was two-fold higher than recommended amounts $(>2400$ $\mathrm{mg}$ ) and Fischer et al. [24] found an average sodium intake of $3412 \mathrm{mg}$ in youths aged 9-18 years with the key food contributors being breads, processed meats and pasta dishes. This was further supported by other studies $[25,28]$.
It is of great interest that children closer to the Mediterranean diet reported a higher sodium intake, whereas a greater proportion of overweight/obese children reported low sodium intake. This may partly be explained by the possible under-reporting seen of overweight/obese individuals; although the questionnaires repeatability was validated prior to use. It must be noted that moderate and high KIDMED score $(>4)$ was observed in $38.8 \%$ of overweight/obese children compared to $61.2 \%$ of normal weight children. No differences were observed in the mean physical activity index score between these groups of children (data not shown).

In this work we quantified the association between the level of Mediterranean diet adherence and sodium intake by calculating the OR of exposure, in order to better evaluate the main effect of the dietary habits of the participants on the likelihood of consuming higher quantities of sodium from different foods. A strong association between the level of adherence to Mediterranean diet and sodium intake was observed. This may seem controversial after taking into consideration that adherence to a Mediterranean food pattern has been shown to be associated with substantial reductions in total mortality and cardiovascular disease mortality in adults [7-10]. In addition, studies have also found an inverse association between hypertension incidence, as well as BP levels in individuals following the Mediterranean diet [11,12]. Moreover, it has also been observed that a diet high in olive oil and, fruit and vegetable was inversely associated with hypertension [13] and that a dietary pattern rich in fruit, vegetables, and low-fat dairy products and poor in total and saturated fat can be effective in the prevention of hypertension [14,29]. However, Núñez-Córdoba et al. [16] did not find an association between hypertension and adherence to the classical Mediterranean diet.

A possible explanation of the high sodium intake of children with moderate and high Mediterranean diet adherence is the total food intake. Thirty-four percent (34\%) of total sodium intake was found to be consumed by those foods known as 'healthy' (i.e. bread, processed cereal and white cheese), compared with $18 \%$ that was observed from pizza. These foods which are recommended to be consumed on a daily basis seem to add substantially to the total dietary sodium of an otherwise healthy dietary pattern, due to sodium addition during manufacturing. Processed foods, including breads/ cereals/grains, also contributed heavily to sodium intake in the UK (95\%) and the US [25]. It is estimated that approximately $75 \%$ of dietary sodium is added during food processing; in addition to taste and palatability, sodium also has functional roles in food manufacturing and preservation, although the amounts used often exceed those required [30]. Due to the high consumption, it may be necessary for manufacturers to reduce sodium use. It has been proposed that the most promising 
sodium reduction strategy is to adapt the preference of consumers for saltiness by reducing sodium in products in small steps [31].

Lastly, it must be noted that our results include the overall population and are not confined on high-risk individuals only (i.e. obese children). Studies have found a direct relation between the increase in childhood obesity and the increased prevalence of pediatric hypertension [32]; also sodium has been associated with an increase in $\mathrm{BP}$, direct cardiovascular damage and obesity [33]. The evaluation of total sodium intake from foods alone (excluding table and cooking salt) in this study showed that both obese and normal weight children have a high dietary sodium intake, raising important public health questions for the children's population. Although, sodium intake was not associated with BP levels, the fact that $23 \%$ of the children's population exceeded the current guidelines from food sources alone makes them exposed to higher risk for future development of hypertension. It is also noteworthy that BMI was positively correlated with BP levels, indicating that children of these age groups are susceptible to risk factors that are documented to elevate BP levels [22,34]. Since the agerelated BP rise in both children and adults is well established [34], efforts to reduce sodium intake and decrease the very high prevalence of childhood obesity, which were observed in the GRECO study, are warranted in order to delay or prevent hypertension.

\section{Limitations}

The limitations of this work are mostly due to its crosssectional nature; although a special effort was given during designing the study, implementing and analyzing the results in order to avoid potential confounding. Overweight and obese children may have under-reported food intake leading to information bias. This was addressed by testing the repeatability of the information regarding sodium intake in a sub-sample of schoolchildren of same age and sex. Additionally, it was mentioned that table salt and salt added while cooking was not evaluated on the effect of dietary sodium intake. This would not have been practical since it is difficult to measure it when using a FFQ. Finally, the use of international instead of local food composition tables (due to the incompleteness) may have over-estimated or under-estimated the sodium intake of some foods studied.

In conclusion, high sodium intake from 'hidden' sources was observed in Greek childhood population, with greater intakes found in children closer to the Mediterranean diet. Thus, the childhood population in Greece should be targeted for a sodium reduction program and not only for the ongoing epidemic of obesity. Moreover, the consumption of a dietary pattern close to the Mediterranean seems not to be a panacea for children's health, since greater adherence was associated with higher sodium intake through 'hidden' sources. The later find- ing does not moderate the undoubtable health benefits gained from this traditional dietary pattern, but should stress manufacturers to reduce the amount of sodium added during processing of 'healthy' foods. This information gathered is valuable for health planners that are aware of the consequences of high sodium intake. Planning population preventive services is essential. Starting at childhood in order to decrease incidence of health issues linked to excess sodium intake seems to be very important.

\section{Acknowledgements}

Funding for the study was provided by the General Secretariat of Consumers-Greek Ministry of Development, Hellenic Association of Food and Beverage Companies, Coca Cola Hellas, Coca Cola Hellenic Bottling Company, Cereal Partners Hellas, FAGE S.A., Unilever Hellas, Nestle Hellas, Kraft Foods Hellas. The authors would also like to thank the field investigators of the 'GRECO' study: Aggeliki Birba, Ourania Brella, Zacharoula Giannari, Sotirio Kalamara, Antonia Kanella, Krini Konstantinou, Gioula Likakou, Olga Malisova, Konstantina Marouda, Alexandra Papadatou, Ivi Papaioannou, Eirini Papaisidorou, Olga Tsiotsiou, Niko Voutzouraki. Special thanks go to Dimitra Tzima for her invaluable secretarial help. We also want to thank Dimitrio Bertzeleto and Panagioti Varagianni for their assistance during the study. Warm thanks to all the children and their families throughout the country that participated in this study, as well as to all the teachers who helped to carry out the study during school hours.

There are no conflicts of interest.

\section{References}

1 Kearney PM, Whelton M, Reynolds K, Muntener P, Whelton PK, He J. Global burden of hypertension: analysis of worldwide data. Lancet 2005; 365:217-223.

2 Geleijnse JM, Grobbee DE, Kok FJ. Impact of dietary and lifestyle factors on the prevalence of hypertension in Western populations. J Hum Hypertens 2005; 19:S1-S4.

3 Joffres MR, Campbell NR, Manns B, Tu K. Estimate of the benefits of a population-based reduction in dietary sodium additives on hypertension and its related healthcare costs in Canada. Can J Cardiol 2007; 23:437443.

4 Lurbe E, Cifkova R, Cruickshank JK, Dillon MJ, Ferreira I, Invitti C, et al. Management of high blood pressure in children and adolescents: recommendations of the European Society of Hypertension. $J$ Hypertens 2009; 27:1719-1742.

5 Elliott C. Assessing 1'fun foods': nutritional content and analysis of supermarket foods targeted at children. Obes Rev 2008; 9:368-377.

6 Supreme Scientific Health Council, Ministry of Health and Welfare of Greece. Dietary guidelines for adults in Greece. Arch Hellenic Med 1999; 16:516-524

7 Willett WC. The Mediterranean diet: science and practice. Public Health Nutr 2006; 9:105-110.

8 Arvaniti F, Priftis KN, Panagiotakos DB. Dietary habits and asthma: a review. Allergy Asthma Proc 2010; 31:e1-10.

9 Sánchez-Taínta A, Estruch R, Bulló M, Corella D, Gómez-Gracia E, Fiol M, et al. Martínez-González MA; PREDIMED group. Adherence to a Mediterranean-type diet and reduced prevalence of clustered cardiovascular risk factors in a cohort of 3,204 high-risk patients. Eur J Cardiovasc Prev Rehabil 2008; 15:589-593.

10 Pérez-López FR, Chedraui P, Haya J, Cuadros JL. Effects of the Mediterranean diet on longevity and age-related morbid conditions. Maturitas 2009; 64:67-79. 
11 Estruch R, Martínez-González MA, Corella D, Salas-Salvadó J, RuizGutiérrez V, Covas Ml, et al., Ros E, PREDIMED Study Investigators. Effects of a Mediterranean-style diet on cardiovascular risk factors: a randomized trial. Ann Intern Med 2006; 145:1-11.

12 Barceló F, Perona JS, Prades J, Funari SS, Gomez-Gracia E, Conde M, et al. Mediterranean-style diet effect on the structural properties of the erythrocyte cell membrane of hypertensive patients: the Prevencion con Dieta Mediterranean Study. Hypertension 2009; 54:1143-1150.

13 Nuñez-Cordoba JM, Alonso A, Beunza JJ, Palma S, Gomez-Gracia E, Martinez-Gonzalez MA. Role of vegetables and fruits in Mediterranean diets to prevent hypertension. Eur J Clin Nutr 2009; 63:605-612.

14 Alonso A, de la Fuente C, Martín-Arnau AM, de Irala J, Martínez JA, MartínezGonzález MA. Fruit and vegetable consumption is inversely associated with blood pressure in a Mediterranean population with a high vegetable-fat intake: the Seguimiento Universidad de Navarra (SUN) Study. Br J Nutr 2004; 92:311-319.

15 Alonso A, Beunza JJ, Delgado-Rodríguez M, Martínez JA, MartínezGonzález MA. Low-fat dairy consumption and reduced risk of hypertension the Seguimiento Universidad de Navarra (SUN) cohort. Am J Clin Nutr 2005; 82:972-979.

16 Núñez-Córdoba JM, Valencia-Serrano F, Toledo E, Alonso A, MartínezGonzález MA. The Mediterranean diet and incidence of hypertension: the Seguimiento Universidad de Navarra (SUN) Study. Am J Epidemiol 2009 169:339-346

17 Farajian P, Karasouli K, Risvas G, Panagiotakos DB, Zampelas A. Repeatability and validity of a food frequency and dietary habits questionnaire in children. Circulation 2009; 119:e288.

18 U.S. Department of Agriculture, Agricultural Research Service. USDA National Nutrient Database for Standard Reference, Release 21.

19 Serra-Majem L, Ribas L, Ngo J, Ortega R, Garcia A, Perez C, Aranceta J. Food, youth and the Mediterranean Diet in Spain. Development of KIDMED, Mediterranean Diet Quality Index in children and adolescents. Public Health Nutr 2004; 7:931-935.

20 Kowalski KC, Crocker PRE, Faulkner RA. Validation of the Physical Activity Questionnaire for older children. Pediatr Exerc Sci 2007; 9:174-186.

21 Cole TJ, Bellizzi MC, Flegal KM, Dietz WH. Establishing a standard definition for child overweight and obesity worldwide: international survey. BMJ 2000; 320:1240-1243.
22 US Department of Health and Human Services, National Heart, Lung, and Blood Institute. The fourth report on the diagnosis, evaluation, and treatment of high blood pressure in children and adolescents. 2005

23 Dietary Reference Intakes for water, potassium, sodium, chloride and sulfate. National Academy of Sciences, Institute of Medicine, Food and Nutrition Board, 2004.

24 Fischer PW, Vigneault M, Huang R, Arvaniti K, Roach P. Sodium food sources in the Canadian diet. Appl Physiol Nutr Metab 2009; 34:884-892.

25 Anderson CA, Appel LJ, Okuda N, Brown IJ, Chan Q, Zhao L, et al. Dietary sources of sodium in China, Japan, the United Kingdom, and the United States, women and men aged 40 to 59 years: the INTERMAP study. $J$ Am Diet Assoc 2010; 110:736-745.

26 Pavadhgul P, Sunthonwaraluk S, Srisorachatr S, Temcharoen P. Dietary sodium intake by Semi-Quantitative Food Frequency Questionnaire among undergraduate students of Mahidol University. J Med Assoc Thai 2009; 92 (Suppl 7):S75-S82.

27 Webster JL, Dunford EK, Neal BC. A systematic survey of the sodium contents of processed foods. Am J Clin Nutr 2010; 91:413-420.

28 Meneton P, Lafay L, Tard A, Dufour A, Ireland J, Ménard J, Volatier JL. Dietary sources and correlates of sodium and potassium intakes in the French general population. Eur J Clin Nutr 2009; 63:1169-1175.

29 Sacks FM, Svetkey LP, Vollmer WM, Appel LJ, Bray GA, Harsha D, et al. Effects on blood pressure of reduced dietary sodium and the Dietary Approaches to Stop Hypertension (DASH) diet. N Engl J Med 2001; 344:3-10.

30 Barr SI. Reducing dietary sodium intake: the Canadian context. App / Physiol Nutr Metab 2010; 35:1-8.

31 Dötsch M, Busch J, Batenburg M, Liem G, Tareilus E, Mueller R, Meijer G. Strategies to reduce sodium consumption: a food industry perspective. Crit Rev Food Sci Nutr 2009; 49:841-851.

32 Andrade H, Antonio N, Rodrigues D, Da Silva M, Pêgo M, Providência LA. High blood pressure in the pediatric age group. Rev Port Cardiol 2010; 29:413-432.

33 de Wardener HE, MacGregor GA. Harmful effects of dietary salt in addition to hypertension. J Hum Hypertens $2002 ; 16: 213-223$.

34 Appel LJ; American Society of Hypertension Writing Group, Giles TD, Black HR, Izzo JL, Materson BJ, Oparil S, Weber MA. ASH Position Paper: dietary approaches to lower blood pressure. J Clin Hypertens 2009; 11:358-368. 